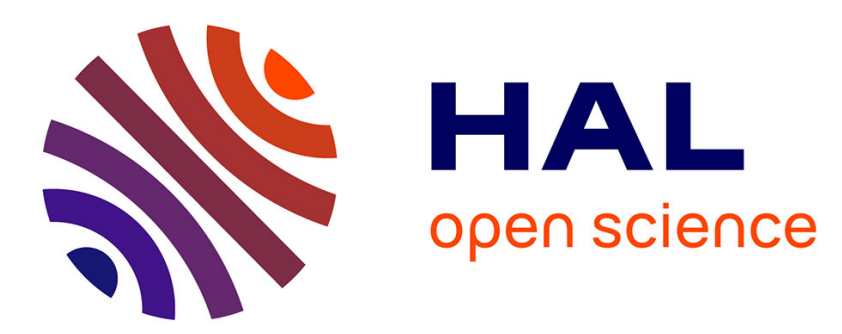

\title{
Towards delayed teleoperation with pneumatic master and slave for MRI
}

\author{
Arnaud Lelevé, Minh Tu Pham, Mahdi Tavakoli, Richard Moreau
}

\section{To cite this version:}

Arnaud Lelevé, Minh Tu Pham, Mahdi Tavakoli, Richard Moreau. Towards delayed teleoperation with pneumatic master and slave for MRI. ESDA2012, Jul 2012, Nantes, France. pp.82782, 10.1115/ESDA2012-82782 . hal-00729081

\section{HAL Id: hal-00729081 \\ https://hal.science/hal-00729081}

Submitted on 29 Jan 2016

HAL is a multi-disciplinary open access archive for the deposit and dissemination of scientific research documents, whether they are published or not. The documents may come from teaching and research institutions in France or abroad, or from public or private research centers.
L'archive ouverte pluridisciplinaire HAL, est destinée au dépôt et à la diffusion de documents scientifiques de niveau recherche, publiés ou non, émanant des établissements d'enseignement et de recherche français ou étrangers, des laboratoires publics ou privés. 


\title{
Towards Delayed Teleoperation with Pneumatic Master and Slave for MRI
}

\author{
Arnaud Leleve ${ }^{1}$, Minh Tu Pham ${ }^{1}$, Mahdi Tavakoli ${ }^{2}$, Richard Moreau ${ }^{1}$
}

\begin{abstract}
Over the last 50 years, master-slave teleoperation has become a widespread and successful field of research. This discipline explores how to perform tasks using a robot on an environment with haptic feedback about robot-environment interaction being provided to the human operator. Most of the master and slave manipulators used in teleoperation are electrically actuated. However, in some particular applications such as inside an MRI for image-guided surgery, ferromagnetic materials including electrical wiring is prohibited. Thus, nonferromagnetic actuators like pneumatic or hydraulic actuators are a solution to this problem. This specific application also requires teleoperation in the sense of "tele-actuation" because of the lack of space inside the MRI chamber to put the robot's actuators and the presence of electrical components in pneumatic servovalves.

In this paper, we study the case of a teleoperation system composed of two identical pneumatic cylinders (as the master and the slave) equipped with servovalves, making a symmetric teleoperation system. This serves as a one-degree-of-freedom system to outline the design and analysis in terms of teleoperation transparency and stability. Simulation and experimental results check the validity of the theory without and with classical transmission delays.
\end{abstract}

- $r$ Perfect gas constant: $r=8.314 / 0.029 \mathrm{~J} /(\mathrm{kg} . \mathrm{K})$

- $k$ Polytropic constant: $k=1.2$

- TSupply temperature: $T=293.15 \mathrm{~K}$

- $M$ Mass of the load: $M=0.5 \mathrm{~kg}$

- SPiston area: $S=1.814 .10^{-4} \mathrm{~m}^{2}$

- $V_{0}$ Dead volume: $V_{0}=10^{-6} \mathrm{~m}^{3}$

- $P_{s}$ Source pressure: $P_{s}=5.210^{5} \mathrm{~Pa}$

- $P_{e}$ Exhaust pressure: $P_{e}=10^{5} \mathrm{~Pa}$

- $b$ Viscosity coefficient: $b=50 \mathrm{~N} /(\mathrm{m} . \mathrm{s})$

- $y(t)$ Load position, in $\mathrm{m}$

- $\dot{y}(t)$ Load rate, in $\mathrm{m} / \mathrm{s}$

- $\ddot{y}(t)$ Load acceleration, in $\mathrm{m} / \mathrm{s}^{2}$

- $\ell$ Stroke length with $0<y<\ell$, in $\mathrm{m}$

- $V_{p}(t), V_{n}(t)$ Volumes of the chambers $P$ and $N$, in $\mathrm{m}^{3}$

- $P_{p}(t), P_{n}(t)$ Pressures in the chambers $P$ and $N$, in Pa

- $q_{p}(t), q_{n}(t)$ Mass flow rates entering in the chambers $P$ and $N$, in $\mathrm{kg} / \mathrm{s}$

- $f_{\text {ext }}(t)$ External longitudinal force exerted by the environment on the piston, in $\mathrm{N}$

\section{INTRODUCTION}

Teleoperation aims to allow a human operator to carry out a sensing or manipulation task in an environment that

\footnotetext{
${ }^{1}$ These authors are with Laboratoire Ampre, UMR CNRS 5005, Université de Lyon, INSA-LYON, F-69621 Villeurbanne Cedex, France arnaud. leleveeinsa-lyon.fr

${ }^{2}$ This author is with Telerobotic and Biorobotic Systems Group, University of Alberta, Edmonton, Canada mahdi.tavakoli@ualberta.ca
}

is not amenable to direct interaction (for instance, in nuclear [1], deep water [2] or space environments [3]). The interaction between the human, the teleoperator, and the environment needs to be controlled so that to ensure a high level of "fidelity" defined as the accurate transmissions of the environments mechanical properties to the human operator [4]. Bilateral teleoperation systems have been developed for various applications ranging from telesurgery to space exploration [1], [5].

Teleoperation of robots has become, over the last decades, a very active and productive field of research with fruitful theoretical results and successful applications [4]. As teleoperation systems are increasingly linked over long distances or computer networks, communication delays become nonnegligible, which can potentially make the whole system unstable. This is why researchers propose different strategies to overcome this weakness such as the use of passivity based approaches (recently summed up in [6], featuring scattering variables [7], wave variables (at first based on 2-channel teleoperation [8] and then extended to 4-channel teleoperation [9]) and predictive/observation based schemes (from Smith predictor [10] to to disturbance observer based control [11]) and model predictive control [12]. From a technological point of view, most of the master and the slave manipulators used in teleoperation are electrically actuated. However, in some particular applications such as inside an MRI room, ferromagnetic materials and electrical wires are prohibited [13]. Non-ferromagnetic actuators such as pneumatic or hydraulic cylinders are a solution to this problem. Because of the lack of space inside the MRI tunnel chamber and the presence of electrical component in pneumatic servovalves, we also have to place the robot actuators at the distance from the MRI scanner.

In this paper, we study the case of a teleoperation system composed of two pneumatic cylinders (one per master/slave) equipped with servovalves, used to form a symmetric teleoperation system (i.e., similar cylinders for the master and the slave). This one-degree-of-freedom example is given to outline the design and analysis in terms of transparency and stability of teleoperation. Simulation and experimental verify check the validity of the theory without and with classical transmission delays.

This paper is organized as follows. We first review models for pneumatic actuators equipped with servovalves [14], [15]. A servovalve characterization and a tangent linearized model used for the control law are given. Then, stability and performance results for constant transmission delays are depicted in simulation and experimentation on a 4 channel teleoperation scheme. Simulation and experimental results are presented to validate the model and controller choices. 


\section{Modelling}

\section{A. Pneumatic Actuator}

Each electropneumatic system used in this paper is composed of the following components: a Moog Atchley Controls $\AA$ jet-pipe servovalve, a symmetric pneumatic cylinder and a mass in translation. The electropneumatic system model can be obtained using three physical laws: the mass flow rate through a geometrical restriction, the pressure behavior in a chamber with variable volume and Newton's second law.

The two servovalves are identical. In our application, their bandwidth is supposed to be greater than that of cylinders so that the dynamics of the servovalves are neglected and their models can be reduced to a static model described by two relationships $q_{p}\left(u_{p}, P_{p}\right)$ and $q_{n}\left(u_{n}, P_{n}\right)$ between the mass flow rates $q_{p}$ and $q_{n}$, the input voltages $u_{p}$ and $u_{n}$, and the output pressures $P_{p}$ and $P_{n}$. The pressure and temperature evolution laws in a chamber with variable volume are obtained assuming the following assumptions [16]. Air is a perfect gas and its kinetic energy is negligible and the pressure and the temperature are homogeneous in each chamber. Moreover, the process is polytropic and characterized by the coefficient $k$. The temperature variation in chambers is negligible with respect to the supply temperature. Finally, the mass flow rate leakages are negligible, and the supply and exhaust pressures are constant.

The following electropneumatic system model is obtained:

$$
\left\{\begin{aligned}
\dot{P}_{p}(t) & =\frac{k r T}{V_{p}(y)}\left[q_{p}\left(u_{p}(t), P_{p}(t)\right)-\frac{S}{r T} P_{p}(t) v(t)\right] \\
\dot{P}_{n}(t) & =\frac{k r T}{V_{n}(y)}\left[q_{n}\left(u_{n}(t), P_{n}(t)\right)+\frac{S}{r T} P_{n}(t) v(t)\right] \\
\ddot{y}(t) & =\frac{1}{M}\left[S P_{p}(t)-S P_{n}(t)-f_{f}(t)-f_{\text {ext }}(t)\right] \\
\dot{y}(t) & =v(t)
\end{aligned}\right.
$$

where the chamber volumes are defined as follows:

$$
\left\{\begin{array}{l}
V_{p}(y)=V_{0}+y(t) S \\
V_{n}(y)=V_{0}+(\ell-y(t)) S
\end{array}\right.
$$

In our application, stiction is ignored in the expression of the friction force $f_{f}$ since we use antistiction

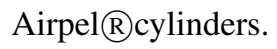

\section{B. Servovalve}

The main difficulty with the model in Eqn. (1) is to know the mass flow rates $q_{p}\left(u_{p}, P_{p}\right)$ and $q_{n}\left(u_{n}, P_{n}\right)$. In order to establish a mathematical model of the power modulator flow stage, many papers present approximations based on physical laws [17], [18] by modelling the geometrical variations of the restriction areas of the servovalve as well as by experimental local mass flow rate characterization [19]. These methods are based on approximations of fluid flow through a convergent nozzle in turbulent regime, corrected by a coefficient $C_{q}$ [20] or on the norm ISO 6358.

In this paper, we propose to use the results of the global experimental method giving the static characteristics of the

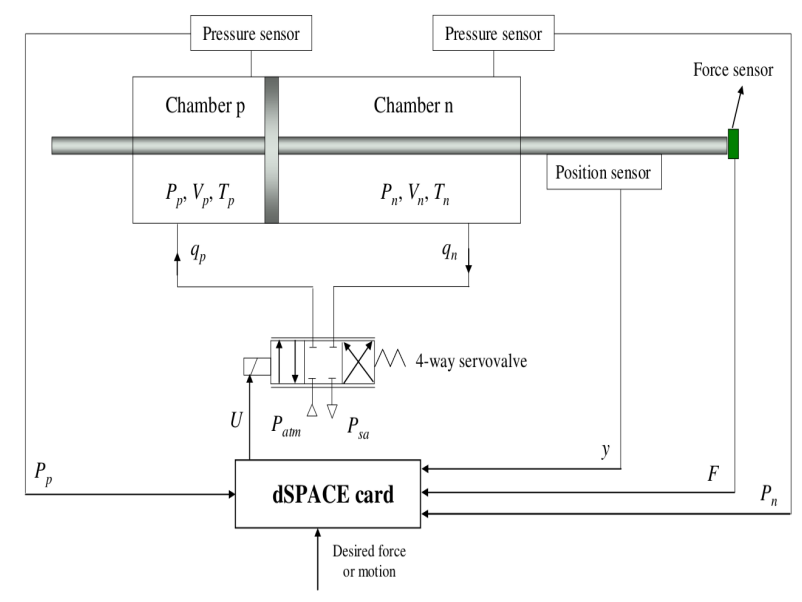

Fig. 1. ELECTRO-PNEUMATIC SYSTEM

flow stage [21]. The global characterization (Fig. 2) corresponds to the static measurement of the output mass flow rate $q$ depending on the input control $u$ and the output pressure $P$ for a constant source pressure. Fig. 2 clearly shows the nonlinear behavior of the flow rate evolution according to the pressure and the input control. The global characterization has the advantage of obtaining simply, by projection of the characteristics series $q(u, P)$ on different planes,

- the mass flow rate characteristics series (plane " $P-q$ "),

- the mass flow rate gain characteristics series (plane " $u$ q"),

- the pressure gain characteristics series (plane " $u-P$ ").

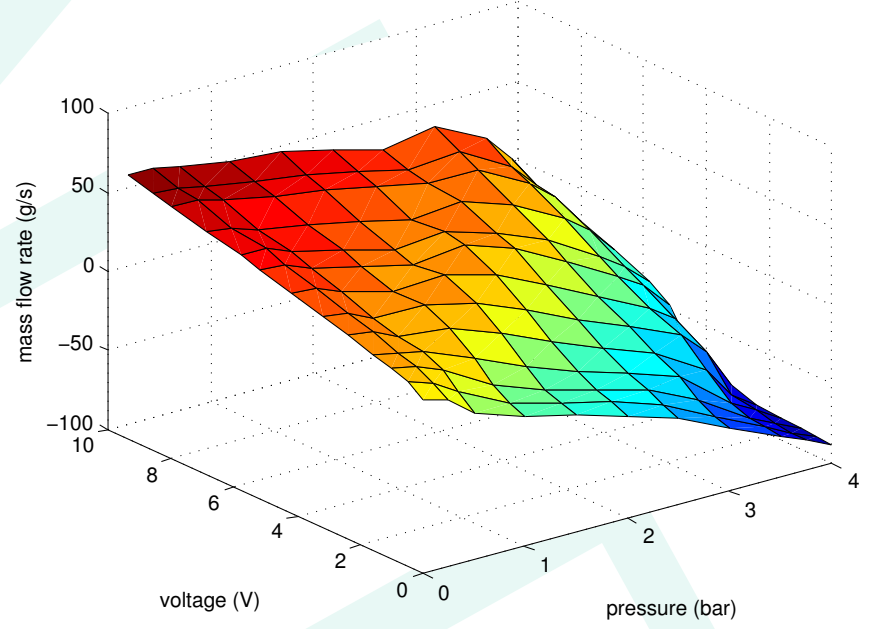

Fig. 2. GLOBAL ATCHLEY SERVOVALVE STATIC CHARACTERISTICS

The authors in [22] have developed analytical models for both simulation and control purposes. Two cases have been studied to approximate the flow stage characteristics by polynomial functions:

- a polynomial approximation affine in control such as:

$$
q(u, P)=\varphi(P)+\psi(P, \operatorname{sign}(u)) u
$$


$\varphi(P)$ in Eqn. (3) is a polynomial function whose evolution corresponds to the mass flow rate leakage, it is identical for all input control value $u . \psi(P, \operatorname{sign}(u))$ is a polynomial function whose evolution is similar to the one described by the methods based on approximations of mass flow rate through a convergent nozzle in turbulent regime [20].

- a multivariable polynomial function

$$
q(u, P)=\sum_{i=0}^{i=N} \sum_{j=0}^{j=M} a_{i j} u^{i} P^{j}
$$

In this paper we use the second approximation because it allows to give a more accurate approximation. Fig. 3 shows the mass flow rate error between the analytical model Eqn. (4) and the measurements with $N=M=3$ in the multivariable polynomial function. For a discussion and more details on the choice of the approximation model and the degrees please refer to [22]. The error shown in

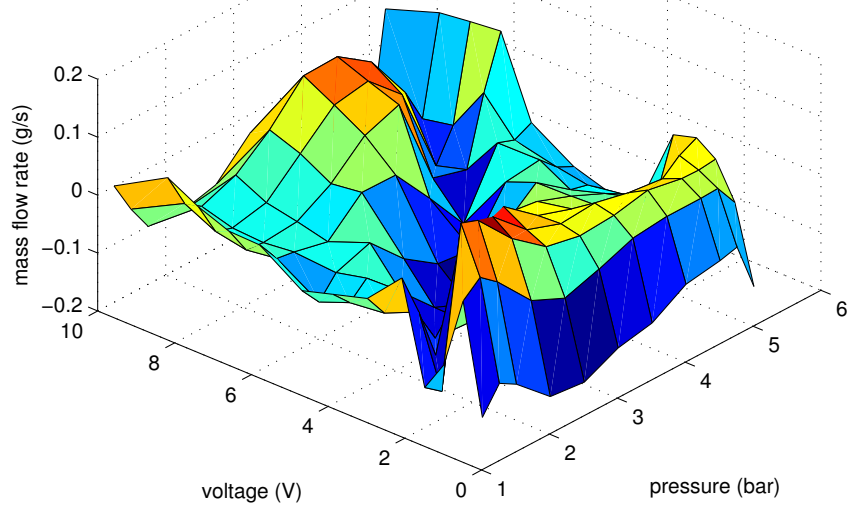

Fig. 3. ATCHLEY SERVOVALVE MASS FLOW RATE ERROR

Fig. 3 describes a polynomial approximation which fits the actual data extremely closely. This approximation is used to estimate the mass flow rates $q_{n}\left(u_{p}, P_{p}\right)$ and $q_{n}\left(u_{n}, P_{n}\right)$ in Eqn. (1).

\section{Tangent Linearized Model}

In order to design a teleoperation controller, a tangent linearized model (denoted with the exponent $e$ ) around a set point, has been established from the nonlinear model Eqn. (1) [23].

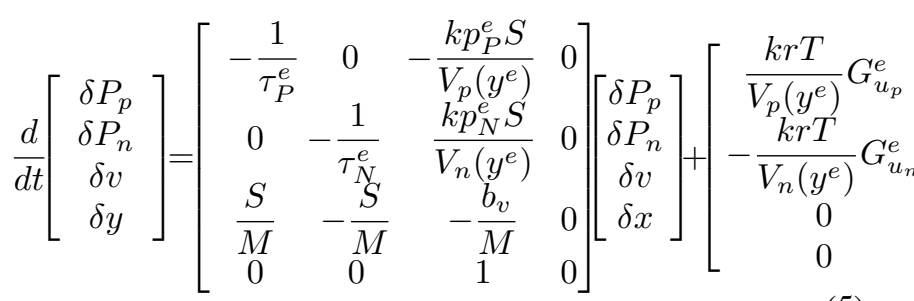

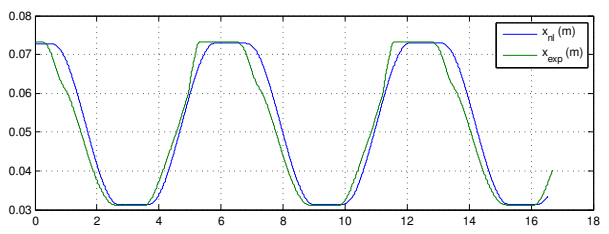

Fig. 4. POSITION TIME RESPONSE FOR A 1 RAD/S INPUT VOLTAGE

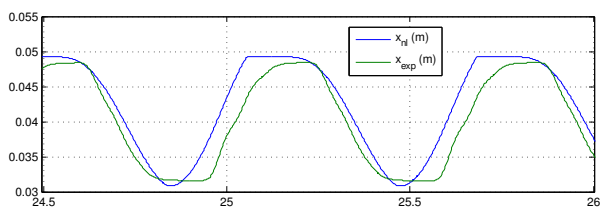

Fig. 5. SUPERPOSED POSITION TIME RESPONSE FOR A 10 RAD/S INPUT VOLTAGE IN STEADY STATE

With the time constants $\tau_{P}^{e}$ and $\tau_{N}^{e}$ defined by:

$$
\tau_{P}^{e}=-\frac{V_{p}\left(y^{e}\right)}{k r T C_{P_{p}}^{e}} \text { and } \tau_{N}^{e}=-\frac{V_{n}\left(y^{e}\right)}{k r T C_{P_{n}}^{e}}
$$

And the mass flow rate sensibility coefficients with respect to the pressures $P$ and the control $u$ are deduced from the nonlinear global static characteristic of the servovalves:

$$
\left\{\begin{array}{c}
C_{P_{p}}^{e}=-\left.\frac{\partial q_{p}\left(u_{p}^{e}, P_{p}\right)}{\partial P_{p}}\right|_{e}, \quad G_{u_{p}}^{e}=\left.\frac{\partial q_{p}\left(u_{p}, P_{p}^{e}\right)}{\partial u_{p}}\right|_{e} \\
C_{P_{n}}^{e}=\left.\frac{\partial q_{n}\left(u_{n}^{e}, P_{n}\right)}{\partial P_{n}}\right|_{e}, \quad G_{u_{n}}^{e}=-\left.\frac{\partial q_{n}\left(u_{n}, P_{n}^{e}\right)}{\partial u_{n}}\right|_{e}
\end{array}\right.
$$

The model Eqn. (5) leads to the third order transfer function given by Eqn. (8)

$$
\frac{Y(s)}{U(s)}=\frac{\Lambda}{s\left(s^{2}+2 \xi \omega_{o} s+\omega_{o}^{2}\right)}
$$

where $\Lambda, \xi$ and $\omega_{o}$ are three constants, which depend on the parameters of the system.

This model provides a good trade-off between performances and complexity when the system is in steady state and around the set point.

\section{Model Validation}

\section{1) Nonlinear Model Validation:}

In order to evaluate the accuracy of the previous actuator and servovalve models, we carried out time response comparisons.

Figure 4 shows the position time response of the nonlinear model $\left(x_{N L}\right)$ and the system $\left(x_{e x p}\right)$ for a sine wave voltage input at $1 \mathrm{rad} / \mathrm{s}$. The behavior of the model is relatively close to the actual system.

The time response obtained for a sine input voltage at 10 $\mathrm{r}$ d d/s is given in Figure 5, in steady state. It appears that the proposed nonlinear model exhibits good qualities to predict the behavior of the system while analyzing the responses to harmonic excitations at different frequencies up to $10 \mathrm{~Hz}$. 

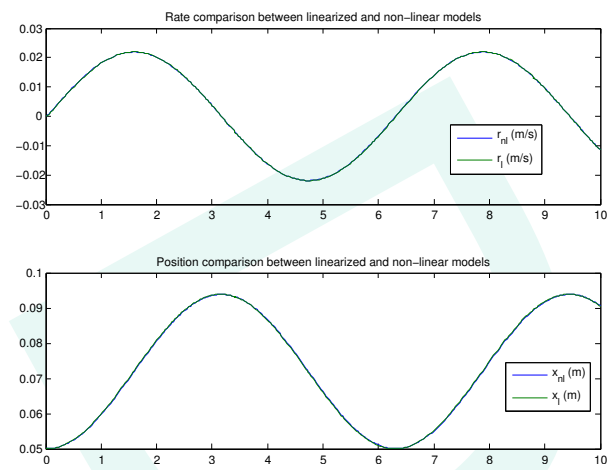

Fig. 6. POSITION AND SPEED COMPARISON BETWEEN LINEAR AND NON-LINEAR MODELS FOR A 1RAD/S INPUT VOLTAGE

\section{2) Tangent Linearized Model Validation:}

Like previously, the frequency response allows to analyze the tangent linearized model properties such as performance and robustness compared to the actual system. A simulation comparison has been carried out between the linear $\left(x_{L}\right)$ and and nonlinear $\left(x_{N L}\right)$ models. Figure 6 highlights that a relative error $\left.\left(\left|x_{N L}-x_{L}\right| /\left|x_{N L}\right|\right)\right)$ of $2,5 \mathrm{e}-3$ is obtained along a $10 \mathrm{~s}$ sinusoidal trajectory at $1 \mathrm{rad} / \mathrm{s}$ and with an amplitude of $10 \mathrm{~cm}$ (stroke length of the rod). Beyond the pulsation of $10 \mathrm{rad} / \mathrm{s}$, the analysis does not present interesting conclusions since the bandwidth of the system is limited.

\section{Teleoperation of Pneumatic actuators}

In the following the master cylinder will be assigned $m$ suffix and the slave one $s$. Thus $y_{m}$ (resp. $y_{s}$ ) represents the position of the master (resp. slave) cylinder.

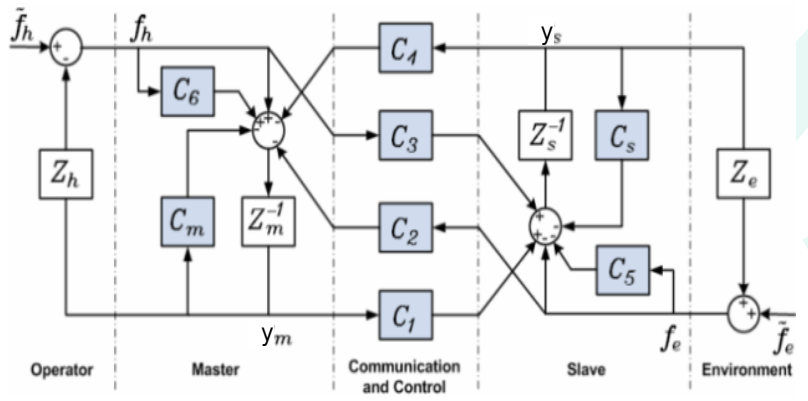

Fig. 7. 4 CHANNEL BILATERAL TELEOPERATION ARCHITECTURE

Several teleoperation architectures exist in the literature. They are usually classified according to the number of channels (transmitted variables) required $(2,3$ or 4$)$ and their type (force or position/rate). The impedances $Z_{m}(s)$, $Z_{s}(s), Z_{h}(s)$ and $Z_{e}(s)$ in Fig. 7 represent the dynamic characteristics of the master robot, the slave robot, the human operator's hand and the remote environment, respectively. This 4-channel of Fig. 7 architecture can represent other teleoperation structures through appropriate selection of subsystem dynamics $C_{1}$ to $C_{6}$ and suggests to use the controllers $C_{s}(s)$ and $C_{m}(s)$ to modify the position control dynamics of the manipulators locally. It has been shown that the fourchannel structure makes it possible to reach, theoretically, the conditions of perfect transparency. Transparency is an essential requirement in order to allow the human operator to safely and precisely perform bilateral teleoperation tasks. It involves providing to the operator a resistive effort $\left(-f_{h}\right)$ equal to the one exerted by the environment on the slave $\left(f_{e}\right)$. Local force loops on each side of the teleoperation system add two other more degrees of freedom to the controller [24]. These local loops are represented by the blocks $C_{5}(s)$ and $C_{6}(s)$ in Fig. 7. Generally, they are simple gains, which make it possible to reach the perfect transparency with only three channels. In [5], Tavakoli et al. discuss this 4-channel architecture and also depict two 2-channel architectures:

- Position Error Based (PEB) control, where the positions of master and slave are exchanged,

- Direct Force Reflection (DFR) control, where the master position is transmitted to the slave while the slave/environment interaction $\left(f_{e}\right)$ is transmitted back to the master.

Note that PEB is known to provide good position tracking but less-than-ideal force tracking, contrary to DFR or 4channel architecture, which provide generally good performances in terms of both position and force tracking.

In this paper, a four-channel architecture (where position and forces are exchanged) has been used. This architecture requires force sensors on both sides, which makes it more expensive than the two-channel schemes. In some teleoperation applications, when force sensors are expensive, cumbersome and susceptible to overload, a hand observer (HOB) [25] or an environment observer (EOB) [26] becomes a good alternative for force estimation. Nonetheless, a main drawback of force observers is that they are generally designed based on the exact knowledge of the master-slave dynamics and kinematics, which are sometimes difficult to determine.

\section{A. Transparency study}

The concept of transparency is associated with the performance of the teleoperation system. Perfect transparency is reached when the user has the feeling of handling the environment directly, without feeling the dynamic effects of the master or the slave manipulators, nor those of the manipulator slave [27]. In the literature, several definitions of the transparency have been proposed. Among the most quoted ones, the correspondence of impedance between that felt by the user and that of the environment [28] makes it possible to describe the degree of transparency. If the slave manipulator is in contact with the environment and the master interface is maintained by the user throughout the operation, it is then possible to establish a mathematical relationship between movements and forces on each side.

The hybrid matrix introduced in [29] is often used to quantify the transparency of a teleoperation system:

$$
\left[\begin{array}{c}
f_{h} \\
-y_{s}
\end{array}\right]=H\left[\begin{array}{c}
y_{m} \\
f_{e}
\end{array}\right]=\left[\begin{array}{ll}
h_{11} & h_{12} \\
h_{21} & h_{22}
\end{array}\right]\left[\begin{array}{c}
y_{m} \\
f_{e}
\end{array}\right]
$$

As Tavakoli et al. explained in [30], each element of the Hmatrix has a physical meaning. For instance, the parameter 
$h_{11}$ corresponds to the input impedance in free-motion condition. Nonzero values for $h_{11}$ mean that even when the slave is in free space, the user will receive some force feedback, thus providing a sticky feel of free-motion movements. The parameter $h_{12}$ is a measure of force tracking when the master is locked in motion (perfect force tracking when $h_{12}=$ 1). The parameter $h_{21}$ is a measure of position (or rate, according to transmitted variables) tracking performance when the slave is in free space (perfect position/rate tracking when $h_{21}=-1$ ). The parameter $h_{22}$ is the output admittance when the master is locked in motion. Nonzero values for $h_{22}$ indicate that even when the master is locked in place, the slave will move in response to slave/environment contacts. Note that the H-parameters contain all the characteristics of the teleoperation system. Furthermore, they are easy to determine through two simple experiments where $f_{e}=0$ (i.e., slave in free space) and $y_{m}=0$ (i.e., master in hard contact). The above conditions lead to an ideal hybrid matrix $H_{\text {ideal }}$ representing ideal transparency:

$$
H_{\text {ideal }}=\left[\begin{array}{cc}
0 & 1 \\
-1 & 0
\end{array}\right]
$$

Based on Fig. 7, straightforward computations give the following controller choices to achieve ideal transparency [5]:

$$
\begin{aligned}
& C_{1}=Z_{s}+C_{s} \\
& C_{2}=1+C_{6} \\
& C_{3}=1+C_{5} \\
& C_{4}=-Z_{m}-C_{m}
\end{aligned}
$$

Let us define $C_{2}=1+C_{6}=C_{f_{m}}$ (master force controller) and $C_{3}=1+C_{5}=C_{f_{s}}$ (slave force controller). Since master and slave devices are supposed to be identical, these latter controllers can be chosen as simple gains: $C_{f_{m}}=C_{f_{s}}=C_{f}$. Transparency conditions then lead to $C_{5}=C_{6}=C_{f}-1$. Since the teleoperation system is held by a human operator, its bandwidth will be limited in practice. That means at low frequencies, we can neglect $Z_{m}$ (and $Z_{s}$ ) compared to $C_{m}$ (and $C_{s}$ ) in order to design simple but efficient controllers. In this case, $C_{4}=-C_{m}=-C_{y}$ (resp. $C_{1}=C_{s}=C_{y}$ ). To sum up, the $H$ matrix coefficients can then be computed according to

$$
\begin{aligned}
h_{11} & =\frac{\left(Z_{s}+C_{s}\right)\left(Z_{m}+C_{m}\right)+C_{1} C_{4}}{D} \\
h_{12} & =\frac{\left(Z_{s}+C_{s}\right) C_{2}-\left(1+C_{5}\right) C_{4}}{D} \\
h_{21} & =-\frac{\left(Z_{m}+C_{m}\right) C_{3}+\left(1+C_{6}\right) C_{1}}{D} \\
h_{22} & =-\frac{C_{2} C_{3}-\left(1+C_{5}\right)\left(1+C_{6}\right)}{D} \\
D & =-C_{3} C_{4}+\left(Z_{s}+C_{s}\right)\left(1+C_{6}\right)
\end{aligned}
$$

which leads to

$$
\begin{aligned}
h_{11} & \left.=\frac{Z_{s}}{C_{f}} \text { (instead of } 0\right) \\
h_{12} & =1 \\
h_{21} & =-1 \\
h_{22} & =0
\end{aligned}
$$

Note that $h_{11}=\left.\frac{f_{h}}{y_{m}}\right|_{f_{e}=0}$ is the input impedance in the free-motion condition. In our case, its nonzero value will provoke, when the slave is in free space, a force feedback that the operator will feel.

\section{B. Stability analysis}

While assuming the operator and environment models are constant-mass spring and damper systems [31], the stability analysis is equivalent to studying the stability of the closedloop $H_{c l}(s)=\frac{X_{m}(s)}{F_{h}(s)}$, according to Hannaford in [29]. The corresponding open loop transfer function is given by Eqn. (14):

$$
L(s)=\frac{\left(h_{11} h_{22}-h_{12} h_{21}\right) Z_{e}+h_{11}}{\left(h_{22} Z_{e}+1\right) Z_{h}}=\frac{Z_{e}+Z_{m} / C_{f}}{Z_{h}}
$$

with $Z_{e}=M_{e} s^{2}+B_{e} s+K_{e}, Z_{h}=M_{h} s^{2}+B_{h} s+K_{h}$ and $Z_{m}$ is the (inverted) linearized model of the master actuator given by Eqn. (8).

The denominator $Z_{h}$ of $L(s)$ is a second order polynomial equation with positive coefficients, so the system is stable in open loop. As the open loop transfer function has no zeros in the right half-plane since $Z_{h}$ and $Z_{e}$ are passive, the closed loop is also stable, assuming the linearized model of the actuator is enough realistic for this study.

\section{Effects of transmission delays}

In presence of transmission delays $T_{d}$, the ideal hybrid matrix is given by Eqn. (15):

$$
H_{\text {ideal d }}=\left[\begin{array}{cc}
0 & e^{-s T_{d}} \\
-e^{-s T_{d}} & 0
\end{array}\right]
$$

which involves a natural decrease of transparency quality.

Besides, the open loop transfer function becomes Eqn. (16):

$L_{d}(s)=\frac{\left(h_{11} h_{22}-h_{12} h_{21} e^{-2 s T_{d}}\right) Z_{e}+h_{11}}{\left(h_{22} Z_{e}+1\right) Z_{h}}=\frac{Z_{e} e^{-2 s T_{d}}+Z_{m} / C_{f}}{Z_{h}}$

As this open loop transfer features a pure delay, the closed loop could be unstable depending on the values of $Z_{h}, Z_{m}$, $Z_{e}$ and $T_{d}$.

\section{Simulation results}

In a first approach, simulations have been used to prepare the experimental implementation and confirm the theory. The teleoperation controllers have been designed with the tangent linearized model introduced in Section I-C but all the simulations have been made with the nonlinear model 
presented in Section I-A in order to test the parametric robustness of the control law.

Similar to [32] the operator's hand is supposed to be characterized by a constant-mass spring and damper model $Z_{h}$ :

$$
Z_{h}(s)=K_{h}+B_{h} s+M_{h} s^{2}
$$

where the operator's stiffness, damping and mass are respectively $K_{h}=2000 \mathrm{~N} / \mathrm{m}, B_{h}=50 \mathrm{~N} . \mathrm{s} / \mathrm{m}$ and $M_{h}=$ $0.7 N . s^{2} / m$;

Environment model offers to the slave a free motion when $y_{s} \in\left[\begin{array}{ll}0 & y_{c}\end{array}\right]$ (where $\left.y_{c}=0,075 \mathrm{~m}\right)$ and a contact at position $y_{c}$. It is modeled as an impedance (see Eqn. (18) which is switched according to the cylinder position $y$ compared to $y_{c}$. According to [31], a soft environment could correspond to $Z_{\text {e soft }}=10 s^{2}+100 s+200$ and a stiff environment could be chosen as $Z_{\text {e stiff }}=10^{3} s^{2}+10^{4} s+2.10^{5}$. Free motion means $Z_{e \text { free }}=0$.

$$
Z_{e}(s)=\left\{\begin{array}{lll}
Z_{\text {e free }} & \text { (in free motion: } & \left.y<y_{c}\right) \\
Z_{\text {e stiff } \mid \text { soft }} & \text { (in contact: } & y \geq y_{c} \text { ) }
\end{array}\right.
$$

$C_{f}$ has been set by simulation with a series of trial-error tests (with $C_{y}=0$ ) in order to provide the best and stable force tracking at first. High values create oscillations on environment changes. Low values would provide a poorer force tracking and so a poorer transparency. The position controller $C_{y}$ has been also set by a series of trial-error tests in order to provide the best and stable position tracking. High values make small oscillations appear on master and slave positions.

With both soft and stiff environment, the best values found were $C_{y}=800 \mathrm{~V} / \mathrm{m}$ and $C_{f}=4 \mathrm{~V} / \mathrm{N}$.

To sum up, $C_{2}=C_{3}=4 \mathrm{~V} / \mathrm{N}, C_{2}=C_{3}=-4 \mathrm{~V} / \mathrm{N}$, $C_{1}=-C_{4}=C_{m}=C_{y}=800 \mathrm{~V} / \mathrm{m}$.

The simulation was conducted with a sinusoidal operator force applied on the master. This force generates a freemotion response during 1.5 seconds, then the slave makes contact with a stiff (visible in Fig. 8) or a soft (see Fig. 9) environment. In each figure, the third plot indicates when the slave is in contact with the environment and the fourth one indicates the force applied by the operator. In terms of position tracking performances, during the free-motion phase, the slave follows correctly the master but as soon as the slave makes contact, a small position error may be visible (due to the elasticity and inertia of the environment). Concerning force tracking performances, the force faithfully tracks that of the master without loss of stability while touching the obstacle but in free motion, the operator has to furnish a very small effort to move the master $( \pm 1 N)$. This result of non-full transparency is in conformity with Eqn. (13). As we set $C_{f}$ with the higher possible value, it has the smaller amplitude we can afford.

We ran a few simulations to see how the system would react to different values of transmission delays. As soon these latter reach $10 \mathrm{~ms}$ (see Fig. 10), signals start to be disturbed by small oscillations of $10 \mathrm{~Hz}$. With a delay of $100 \mathrm{~ms}$ (see fig. 11), position and force tracking are quite degraded. Moreover, we can observe a transient response
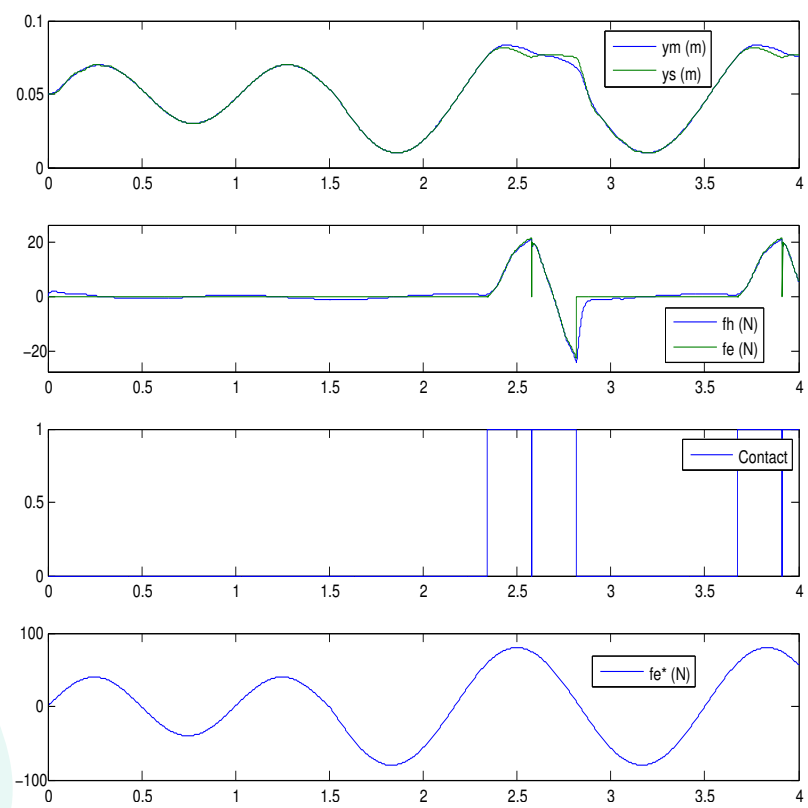

Fig. 8. SIMULATION OF POSITION AND FORCE TRACKING WITH 4 CHANNEL (POSITION FORCE) WITHOUT DELAY AND A STIFF ENVIRONMENT
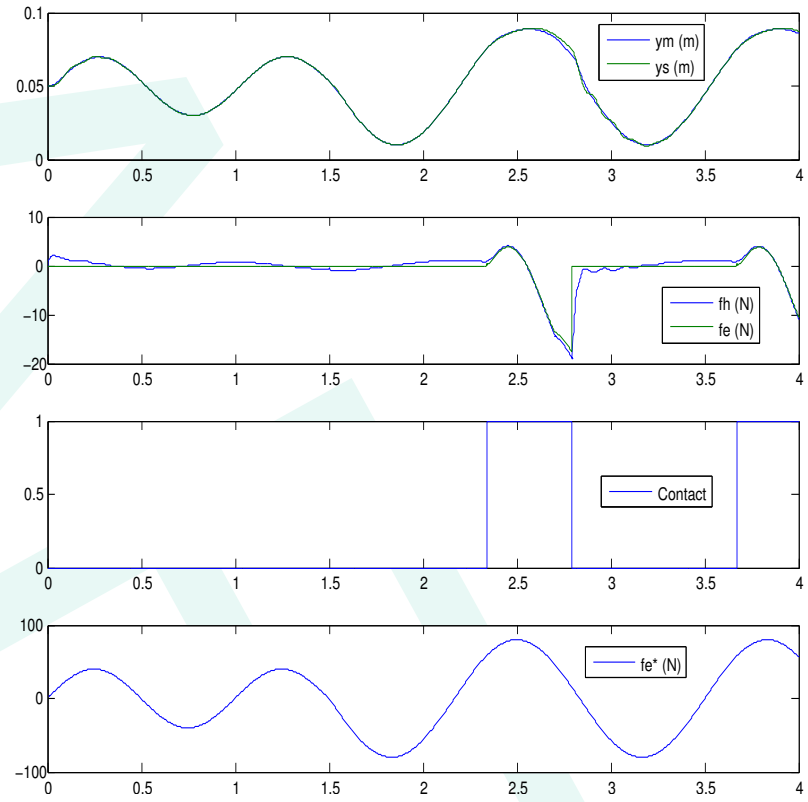

Fig. 9. SIMULATION OF POSITION AND FORCE TRACKING WITH 4 CHANNEL (POSITION FORCE) WITHOUT DELAY AND A SOFT ENVIRONMENT

of one second, on system start, where position tracking is particularly bad. With higher delays, position and force tracking worsens but, interestingly, we could not observe any instability in simulation with this kind of environment in this range of delays.

\section{E. Experimental results}

We built an experimental setup to test the system depict in Fig. 12. Actuators are low-friction cylinders (Airpel model M16D100D) with a $16 \mathrm{~mm}$ inner diameter, a $100 \mathrm{~mm}$ stroke 

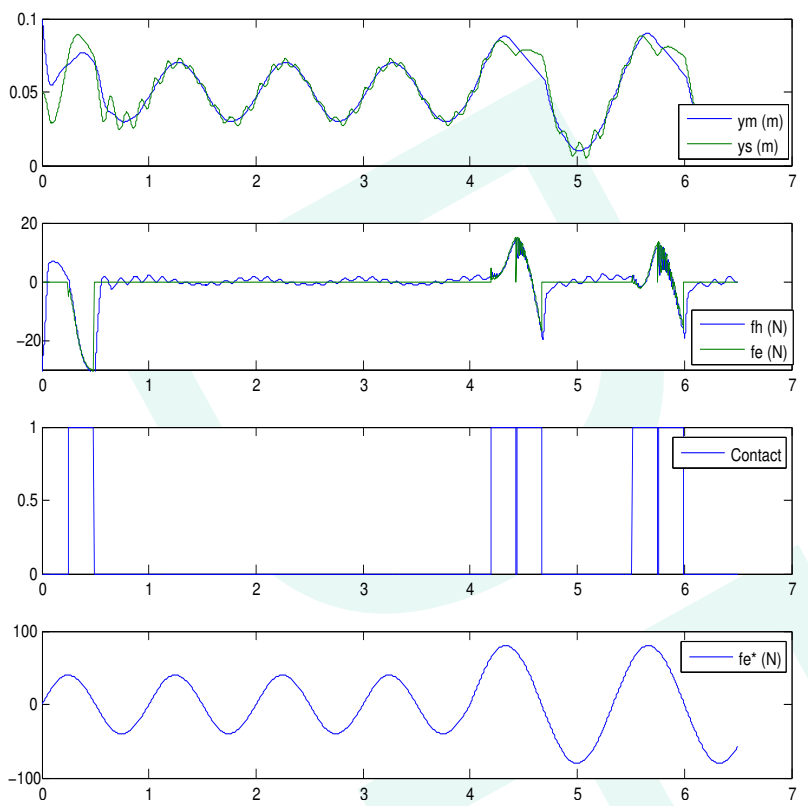

Fig. 10. SIMULATION OF POSITION AND FORCE TRACKING WITH 4 CHANNEL (POSITION FORCE) WITH A TRANSMISSION DELAY OF 10 MS AND A STIFF ENVIRONMENT
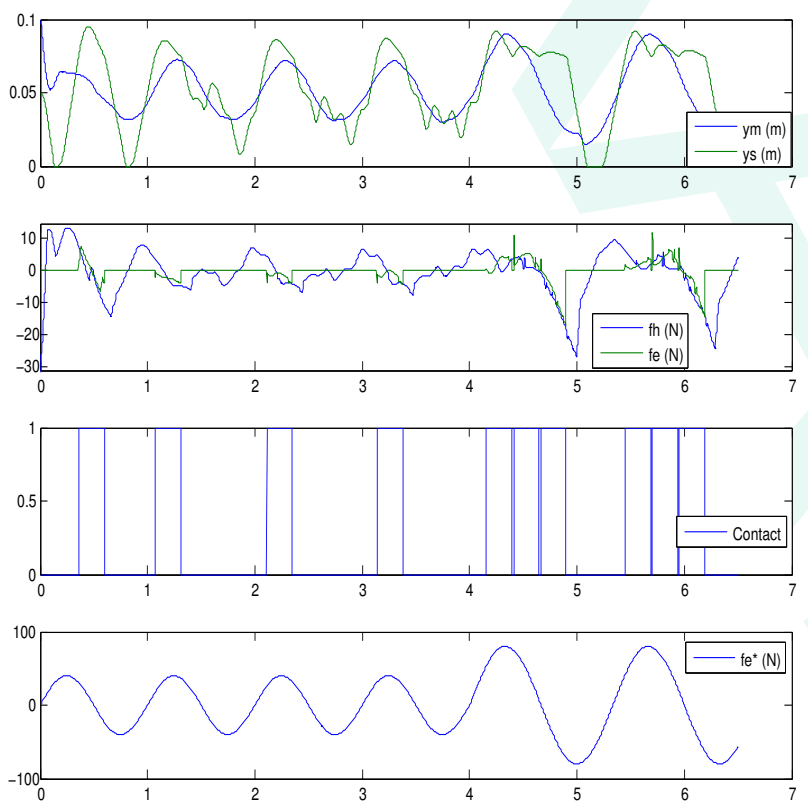

Fig. 11. SIMULATION OF POSITION AND FORCE TRACKING WITH 4 CHANNEL (POSITION FORCE) WITH A TRANSMISSION DELAY OF 100 MS AND A STIFF ENVIRONMENT

length, and a $5 \mathrm{~mm}$ rod diameter. Two jet-pipe servovalves, Atchley 200PN-176, described in Section I-B are used. In terms of sensors, a low-friction linear variable differential transformer (LVDT) is connected to each cylinder in order to measure the master and the slave positions. In addition, each cylinder chamber is equipped with a pressure sensor. The air supply was chosen equal to an absolute pressure of $300 \mathrm{kPa}$. A computer and a dSPACE controller board (DS1104) are used to drive the servovalves. The sampling rate of the controller $(500 \mathrm{~Hz})$ is chosen to be higher than the bandwidth above which the human finger cannot distinguish two consecutive force stimuli which is $320 \mathrm{~Hz}$ [33], [34]. In addition, each of the end-effectors of the master and the slave manipulators is equipped with a force sensor - this will help to measure the operator and the environment forces, respectively. Note that since the distance between the master and slave manipulators is limited to a few meters, their controllers are embedded on one single computer system.

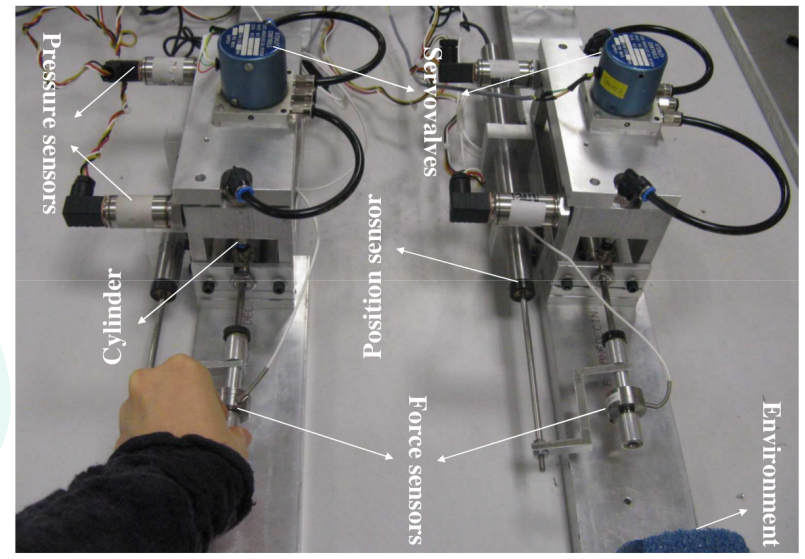

Fig. 12. TELEOPERATION EXPERIMENTAL SETUP USING ELECTRO-PNEUMATIC SERVOVALVES

Note also that with the real system, we had to set $C_{f}=$ $0.5 \mathrm{~V} / \mathrm{N}$ and $C_{y}=500 \mathrm{~V} / \mathrm{m}$ as previous values made the system unstable. A reason for this may be some additional friction and the air leakage in the cylinder (typical of ultra low friction cylinders) and jet-pipe servovalves, which were not integrated in the simulation model.

Without any transmission delay, this four channel (position force) architecture (Fig. 13) provides good results in position and effort tracking during the free-motion but not quite good during contact phase. Interestingly, as mentioned above, free motion displacements require an effort of $( \pm 3 N)$ as this system is not fully transparent. This is more than in previous simulations but the unmodeled characteristics were ought to downgrade the system performances.

With a 100ms transmission delay, position tracking remains good in free motion but the presence of an (even soft) obstacle makes it unstable (Fig. 14) as expected by the theory.

\section{CONCLUSION}

In this paper, a single degree of freedom pneumaticactuator-based teleoperation system is presented. This kind of device can typically be used in a MRI application where electric actuators are prohibited. The actuator model but also the servovalve characterization show the non-linear behavior of such a system. However, around a set point a tangent linearized model of the system could be obtained. This latter model is then used for the design of the control law. Simulations and first experimental data provide encouraging results in terms of position and force tracking with or without transmission delay. Future works will focus on the performance of the tracking either with a refined model or 

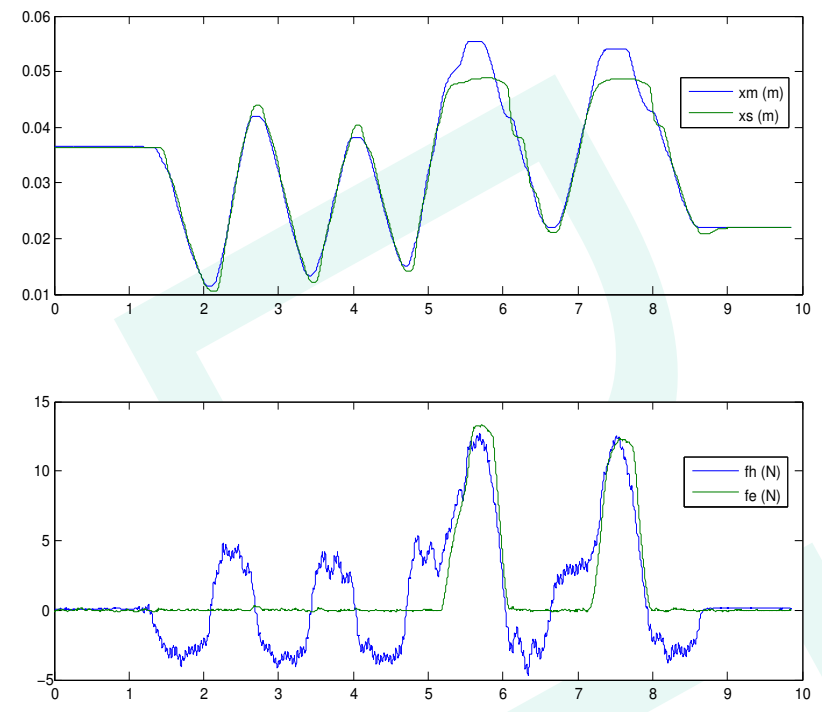

Fig. 13. EXPERIMENTAL RESULTS FOR 4 CHANNEL ARCHITECTURE WITHOUT DELAY
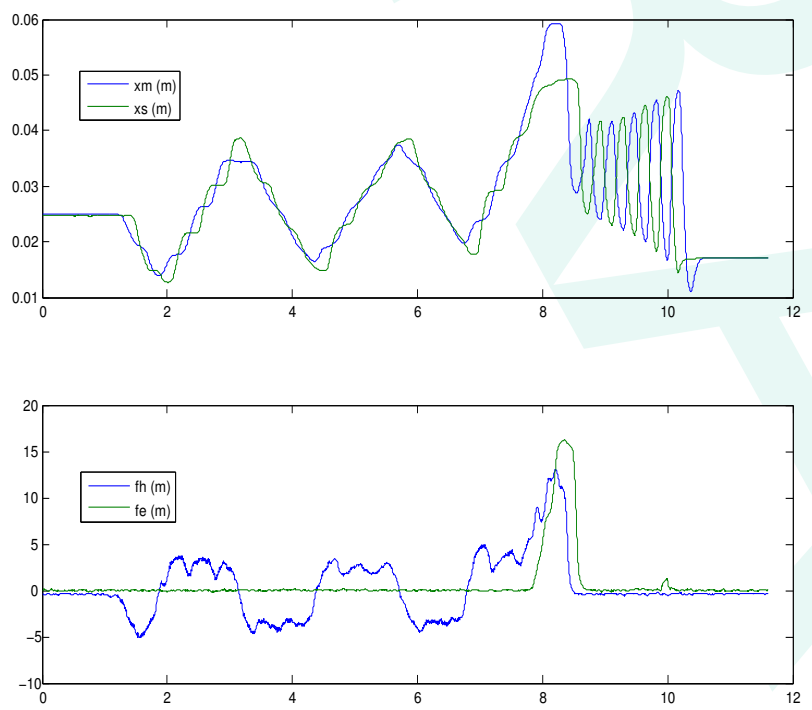

Fig. 14. EXPERIMENTAL RESULTS FOR 4 CHANNEL ARCHITECTURE WITH 100MS TRANSMISSION DELAY

by taking into account the non-linearities of the system and the air transport delays imposed by long hoses.

\section{REFERENCES}

[1] Sabater, J. M., J, R., Saltarn, Aracil, R., Yime, E., and Azorn, J. M., 2006. "Teleoperated parallel climbing robots in nuclear installations". Industrial Robot: An International Journal, 33(6), pp. $381-386$.

[2] Soylu, S., Firmani, F., Buckham, B. J., and Podhorodeski, R. P., 2010. "Comprehensive underwater vehicle-manipulator system teleoperation". In Proc. OCEANS 2010, pp. 1-8.

[3] Yoon, W.-K., Goshozono, T., Kawabe, H., Kinami, M., Tsumaki, Y., Uchiyama, M., Oda, M., and Doi, T., 2004. "Model-based space robot teleoperation of ets-vii manipulator". IEEE Journal of Robotics and Automation, 20(3), pp. 602-612.

[4] Hokayem, P. F., and Spong, M. W., 2006. "Bilateral teleoperation: An historical survey". Automatica, 42(12), pp. 2035 - 2057.

[5] Tavakoli, M., Patel, R. V., Moallem, M., and Aziminejad, A., 2008. Haptics for teleoperated surgical robotic systems. New Frontiers in Robotics. World Scientific Publishing Company. ISBN-10: 9812813152 ISBN-13: 978-9812813152.
[6] Nuo, E., Basaez, L., and Ortega, R., 2011. "Passivity-based control for bilateral teleoperation: A tutorial". Automatica, 47(3), March, pp. 485-495.

[7] Chopra, N., and Spong, M., 2006. "Output synchronization of nonlinear systems with time delay in communication". In Decision and Control, 2006 45th IEEE Conference on, pp. $4986-4992$.

[8] Niemeyer, G., and Slotine, J. J. E., 1991. "Stable adaptive teleoperation". IEEE Journal of Oceanic Engineering, 16(1), pp. 152-162.

[9] Aziminejad, A., Tavakoli, M., Patel, R. V., and Moallem, M., 2008 "Transparent time-delayed bilateral teleoperation using wave variables". IEEE Transactions on Control Systems Technology, 16(3), pp. 548-555.

[10] Smith, A. C., and Hashtrudi-Zaad, K., 2006. "Smith predictor type control architectures for time delayed teleoperation". International Journal of Robotics Research, 25, August, pp. 797-818.

[11] Mohammadi, A., Tavakoli, M., and Marquez, H., 2011. "Disturbance observer-based control of non-linear haptic teleoperation systems". IET Control Theory \& Applications, 5(18), pp. 2063-2074.

[12] Ding, B., 2011. "Stabilization of linear systems over networks with bounded packet loss and its use in model predictive control". Automatica, 47(11), pp. $2526-2533$.

[13] Fischer, G. S., Iordachita, I., Csoma, C., Tokuda, J., DiMaio, S. P., Tempany, C. M., Hata, N., and Fichtinger, G., 2008. "Mricompatible pneumatic robot for transperineal prostate needle placement". IEEE/ASME Transactions on Mechatronics, 13(3), pp. 295305.

[14] Bouri, M., and Thomasset, D., 2001. "Sliding control of an electropneumatic actuator using an integral switching surface". IEEE Transactions on Control Systems Technology, 9(2), pp. 368-375.

[15] Laghrouche, S., Smaoui, M., Brun, X., and Plestan, F., 2004. "Robust second order sliding mode controller for electropneumatic actuator". In Proc. American Control Conf the 2004, Vol. 6, pp. 5090-5095.

[16] Shearer, J., 1956. "Study of pneumatic processes in the continuous control of motion with compressed air: Part I and II". Transactions ASME, 78, pp. 233-249.

[17] Araki, K., 1981. "Effects of valve configuration on a pneumatic servo". International Fluid Power Symposium, pp. 271-290.

[18] Mo, J. P. T., 1989. "Analysis of compressed air flow through a spool". Proceedings of the Mechanical Engineers, 203, pp. 121-131.

[19] Richard, E., and Scavarda, S., 1996. "Comparison between linear and nonlinear control of an electropneumatic servodrive". Journal of Dynamic Systems, Measurement, and Control, 118, pp. 245-252.

[20] Mc Cloy, D., and Martin, H. R., 1980. Control of fluid power: Analysis and design. Ellis Horwood.

[21] Sesmat, S., and Scavarda, S., 1996. "Static characteristics of a three ways servovalve". Conference on Fluid Power Technology, pp. 643652 .

[22] Belgharbi, M., Sesmat, S., Scavarda, S., and Thomasset, D., 1999. "Analytical model of the flow stage of a pneumatic servodistributor for simulation and nonlinear control". Scandinavian International Conference on Fluid Power, pp. 847-860.

[23] Richard, E., 1990. "De la commande linéaire et non linéaire en position des sytème électropneumatiques". PhD thesis, INSA de Lyon.

[24] Hashtrudi-Zaad, K., and Salcudean, S. E., 2002. "Bilateral parallel force/position teleoperation control". Journal of Robotic Systems, 19(4), pp. 155-167.

[25] Nicosia, S., and Tomei, P., 1990. "Robot control by using only joint position measurements". IEEE Transactions on Automatic Control, 35(9), pp. 1058-1061.

[26] Mitsantisuk, C., Ohishi, K., and Katsura, S., 2011. "Estimation of action/reaction forces for the bilateral control using kalman filter". IEEE Transactions on Industrial Electronics(99). Early Access.

[27] Handlykken, M., and Turner, T., 1980. "Control system analysis and synthesis for a six degree-of-freedom universal force-reflecting hand controller". In Proc. 19th IEEE Conf. Decision and Control including the Symp. Adaptive Processes, Vol. 19, pp. 1197-1205.

[28] Lawrence, D. A., 1993. "Stability and transparency in bilateral teleoperation". IEEE Transactions on Robotics and Automation, 9(5), pp. 624-637.

[29] Hannaford, B., 1989. "A design framework for teleoperators with kinesthetic feedback". IEEE Transactions on Robotics and Automation, 5(4), pp. 426-434.

[30] Tavakoli, M., Aziminejad, A., Patel, R. V., and Moallem, M., 2007. "High-fidelity bilateral teleoperation systems and the effect of multimodal haptics". IEEE Transactions on Systems, Man, and Cybernetics, Part B: Cybernetics, 37(6), pp. 1512-1528. 
[31] Salcudean, S. E., Zhu, M., Zhu, W.-H., and Hashtrudi-Zaad, K., 2000. "Transparent bilateral teleoperation under position and rate control". The International Journal of Robotics Research, 19, pp. 1185-1202.

[32] Kazerooni, H., Tsay, T.-I., and Hollerbach, K., 1993. "A controller design framework for telerobotic systems". IEEE Transactions on Control Systems Technology, 1(1), pp. 50-62.

[33] Shimoga, K. B., 1993. "A survey of perceptual feedback issues in dexterous telemanipulation. i. finger force feedback". In Proc. IEEE Virtual Reality Annual Int. Symp., pp. 263-270.

[34] Shimoga, K. B., 1993. "A survey of perceptual feedback issues in dexterous telemanipulation. ii. finger touch feedback". In Proc. IEEE Virtual Reality Annual Int. Symp., pp. 271-279. 